\title{
Identification and Expression Characterization of ATP-Binding Cassette (ABC) Transporter Genes in Melon Fly
}

\author{
Hui-Qian Xu ${ }^{1,2}$, Meng Ma ${ }^{1,2}$, Yun-Peng Ma ${ }^{1,2}$, Su-Yun Zhang ${ }^{1,2}$, Wei-Jun Li ${ }^{1,2}$, Dong Wei ${ }^{1,2, * \mathbb{D}}$ \\ and Jin-Jun Wang ${ }^{1,2, *(D)}$
}

1 Chongqing Key Laboratory of Entomology and Pest Control Engineering, College of Plant Protection, Southwest University, Chongqing 400715, China; endeavorx@163.com (H.-Q.X.); mameng202101@163.com (M.M.); mypeng159@163.com (Y.-P.M.); 18375633196@163.com (S.-Y.Z.); liweijun201608@163.com (W.-J.L.)

2 State Cultivation Base of Crop Stress Biology for Southern Mountainous Land, Academy of Agricultural Sciences, Southwest University, Chongqing 400715, China

* Correspondence: dong_wei1988@yahoo.com (D.W.); wangjinjun@swu.edu.cn (J.-J.W.); Tel.: +86-23-6825-0653 (D.W.); +86-23-6825-0255 (J.-J.W.)

check for

updates

Citation: Xu, H.-Q.; Ma, M.; Ma, Y.-P.; Zhang, S.-Y.; Li, W.-J.; Wei, D.; Wang, J.-J. Identification and Expression Characterization of ATP-Binding Cassette (ABC) Transporter Genes in Melon Fly. Insects 2021, 12, 270. https:// doi.org/10.3390/insects 12030270

Academic Editor: Fabrice Legeai

Received: 19 February 2021

Accepted: 19 March 2021

Published: 23 March 2021

Publisher's Note: MDPI stays neutral with regard to jurisdictional claims in published maps and institutional affiliations.

Copyright: (c) 2021 by the authors. Licensee MDPI, Basel, Switzerland. This article is an open access article distributed under the terms and conditions of the Creative Commons Attribution (CC BY) license (https:/ / creativecommons.org/licenses/by/ $4.0 /)$.
Simple Summary: The melon fly, Zeugodacus cucurbitae, is an important agricultural pest. At present, chemical pesticide treatment is the main method for field control, but this promotes pesticide resistance by Z. cucurbitae, because of its frequent use. ABC transporters are involved in detoxification metabolism, but few studies have yet considered their expression in melon fly. In this study, we identified the $\mathrm{ABC}$ transporters genes at a genome-wide level in melon fly, and analysed their spatiotemporal expression patterns, as well as changes in expression after insecticides treatments. A total of $49 \mathrm{ABC}$ transporters were identified, and their expression levels varied at different developmental stages and between tissues. After three insecticides treatment, $Z_{c} A B C B 7$ and $Z_{c} A B C C 2$ were up-regulated. After $\beta$-cypermethrin induction, tissues were dissected at 12,24 and $48 \mathrm{~h}$, and the expression levels of a number of $A B C$ genes were highly expressed within the fat body. From these results, we conclude that $Z c A B C B 7$ and $Z c A B C C 2$ may be involved in detoxification metabolism, and that the fat body is the main tissue that plays this role.

Abstract: The ATP-binding cassette (ABC) transporter is a protein superfamily that transports specific substrate molecules across lipid membranes in all living species. In insects, ABC transporter is one of the major transmembrane protein families involved in the development of xenobiotic resistance. Here, we report $49 \mathrm{ABC}$ transporter genes divided into eight subfamilies (ABCA-ABCH), including seven $A B C A$ s, seven $A B C B s, 10 A B C C$ s, two $A B C D$ s, one $A B C E$, three $A B C F s, 16 A B C G$ s, and three $A B C H s$ according to phylogenetic analysis in Zeugodacus cucurbitae, a highly destructive insect pest of cucurbitaceous and other related crops. The expressions level of 49 ABC transporters throughout various developmental stages and within different tissues were evaluated by quantitative transcriptomic analysis, and their expressions in response to three different insecticides were evaluated by quantitative real-time polymerase chain reaction (qRT-PCR). These ABC transporter genes were widely expressed at developmental stages but most highly expressed in tissues of the midgut, fat body and Malpighian tube. When challenged by exposure to three insecticides, abamectin, $\beta$-cypermethrin, and dinotefuran, the expressions of $Z c A B C B 7$ and $Z c A B C C 2$ were significantly up-regulated. $Z c A B C B 1$, $\mathrm{ZcABCB6}, \mathrm{ZcABCB7}, \mathrm{ZcABCC}, \mathrm{ZcABCC}$, ZcABCC4, ZcABCC5, and ZcABCC7 were significantly up-regulated in the fat body at $24 \mathrm{~h}$ after $\beta$-cypermethrin exposure. These data suggest that $Z c A B C B 7$ and $Z c A B C C 2$ might play key roles in xenobiotic metabolism in Z. cucurbitae. Collectively, these data provide a foundation for further analysis of ABCs in Z. cucurbitae.

Keywords: Zeugodacus cucurbitae; ABC transporter; transcriptional expression; insecticides; detoxification 


\section{Introduction}

ATP-binding cassette $(\mathrm{ABC})$ proteins comprise one of the largest superfamilies of prokaryote and eukaryote membrane proteins [1]. According to sequence homology and structural similarity, they can be divided into different subfamily members. For example, a total of $48 \mathrm{ABC}$ transporters in humans are divided into seven subfamilies (ABCA to ABCG) [2], while in Drosophila melanogaster, an eighth subfamily (ABCH) was first discovered. This latter member is widely expressed in arthropods and zebrafish but not in mammals, plants and fungi [3,4]. The majority of these $A B C$ proteins comprise two highly conserved structural domains, a nucleotide-binding domain (NBD) that can bind and hydrolyze ATP, and a transmembrane domain (TMD) that is comprised of six membrane-spanning helices [5]. The highly conservative NBD contains three motifs: a Walker A and Walker B domain and the ABC signature motif (LSSG-motif). There are two of these structural domains in $\mathrm{ABC}$ transporters from eukaryotes. These are either half-transporters which have one TMD and one NBD, or full-transporters which have two TMDs and two NBDs, and often form a functional unit as a homo- or heterodimer $[1,6]$. Up until now, the $A B C$ transporters have been widely identified at a genome-wide level in many insect species.

In terms of different functions, $\mathrm{ABC}$ transporters can be divided into three categories: input proteins, output proteins and non-transport proteins [7]. The main function of the input and output proteins is substrate transport, e.g., amino acids, lipids, lipopolysaccharides, peptides, inorganic ions, drugs, metals and xenobiotics [8]. Non-transport proteins have no transport function, but are involved in intracellular DNA repair, transcription and regulation of gene expression [9]. In insects, studies have shown that $A B C$ transporters have roles in development and detoxification, including the metabolism of pesticides, plant secondary metabolic compounds (allelochemicals) and other heterologous substances [10]. In recent years, the important role of $A B C$ transporters in the insect's response to pesticides and other toxic compounds has caused widespread concern [11,12]. In Bemisia tabaci, the ABCG3 subfamily may contribute to imidacloprid detoxification [13]. In Plutella xylostella, four $A B C$ subfamilies ( $A B C A, A B C C, A B C G$, and $A B C H$ ) were increased in a fipronil resistant strain [14]. Similarly, after insecticide exposure, some $A B C$ transporters were up-regulated in mosquito larvae [15]. In Aphis gossypii, $\mathrm{ABC}$ transporters are involved in thiamethoxam resistance [16]. In addition, inhibition of $A B C$ transporter gene expression by RNA interference (RNAi) can increase pesticide toxicity $[17,18]$.

Although the contribution of $\mathrm{ABC}$ transporters to drug resistance in mammals has been extensively studied, the mechanisms by which these $A B C$ transporter genes confer resistance in arthropods remains unclear. The $\mathrm{ABCB}$ subfamily contains multi-drug resistance proteins (MDRs) or P-glycoproteins (P-gps). The ABCC subfamily includes the multidrug-resistance associated proteins (MRPs) in humans, and these are involved in the multidrug resistance of cancer cells to chemotherapy [4]. The detoxification processes in insects are divided into three phases: cytochromes P450 monooxygenase (P450s) and carboxylesterases (CarEs) belong to phase I metabolism, glutathione S-transferases (GSTs) belongs to phase II, while ABC transporters belongs to phase III. Phases I and II can act directly upon a toxin molecule, and then the substrates transported extracellular in phase III $[19,20]$. Therefore, it is crucial to understand the role of ABC for conferring resistance to insecticides.

The melon fly Zeugodacus cucurbitae (Coquillett) (Diptera, Tephritidae) is an important, global, agricultural pest [21]. Z. cucurbitae can infest more than 130 host plants including vegetables and fruits, but mainly gourd and nightshade plants, such as cucumber, pumpkin, melon, watermelon, bitter melon, tomato and eggplant [22] Although the biological control by releasing of parasitoids against Z. cucurbitae was evaluated recently [23], the extensive use of pesticides is the frequently method to control Z. cucurbitae, which leads to serious resistance to a range of insecticides. At present, there are few studies that have considered the $\mathrm{ABC}$ transporters present within the melon fly. Moreover, whether $\mathrm{ABC}$ proteins are also involved in different insecticide detoxifications has not been investigated in $Z$. 
cucurbitae. In this study, we identified 49 ABC transporters from Z. cucurbitae. They were divided into eight subfamilies of $\mathrm{ABCA} \sim \mathrm{ABCH}$. The gene expression profiles were studied at different development stages and within various tissues. Secondly, we focused on an analysis of the expression of $\mathrm{ABC}$ transporters after three different insecticide treatments. Collectively, a more comprehensive analysis of $\mathrm{ABC}$ genes will provide an insight into the physiological function of $\mathrm{ABC}$ transporters, and how this is regulated in response to xenobiotic stimuli.

\section{Materials and Methods}

\subsection{Insects}

Z. cucurbitae were initially collected from Haikou of Hainan Province, China, in 2016, and maintained in the laboratory under conditions of $27 \pm 0.5^{\circ} \mathrm{C}, 14-\mathrm{h} \mathrm{L}: 10-\mathrm{h} \mathrm{D}$ photoperiod, $70 \pm 5 \%$ relative humidity $(\mathrm{RH})$. The insects were fed on an artificial diet, as previously described [24].

\subsection{Identification, Characterization and Phylogenetic Analysis}

To identify ABC transporter genes, we carried out tBlastn searching against the $Z$. cucurbitae genome [25], with highly conserved NBDs present in D. melanogaster ABC transporter genes. The putative $\mathrm{ABC}$ gene sequences were taken as the query objects, and each of the ABC transporter genes was confirmed in the NCBI protein database.

The conserved domains of these Z. cucurbitae ABC proteins were predicted using SMART (http:/ / smart.embl.de, accessed on 14 May 2020) [26]. The signal peptide was analyzed with the online software, SignalP 5.0 Server (http:/ / www.cbs.dtu.dk/services / SignalP, accessed on 14 May 2020). Subcellular localization was predicted using TargetP 2.0 [27]. Transmembrane domains were predicted with the software TMHMM Server v2.0 (http://www.cbs.dtu.dk/services/TM-HMM, accessed on 14 May 2020). The N-glycosylation and O-glycosylation sites were analyzed by NetNGlyc1.0 Server (http: / / www.cbs.dtu.dk/services/NetNGlyc, accessed on 2 July 2020) and NetOGlyc 4.0 server (http: / / www.cbs.dtu.dk/services/NetOGlyc, accessed on 2 July 2020) [28]. Fulllength protein sequences were utilized to construct the respective phylogeny trees using the neighbor-joining method (1000 replicates for bootstrapping) via MEGA 7.0 software.

\subsection{RNA Isolation and $c D N A$ Synthesis}

Three tissues (midgut, fat body, and Malpighian tubule) were dissected from 20 female adult flies, with four replicates of each that includes 4-5 individuals. TRIzol reagent (Invitrogen, Carlsbad, CA, USA) was used to extract total RNA according to the manufacturer's instructions. The concentration and purity of $1.5 \mu \mathrm{L}$ of dissolved RNA for each of the samples were quantified using a Nanodrop ONE spectrophotometer (Thermo Fisher Scientific, Waltham, MA, USA) at absorbance ratios of OD 260/280 and OD 260/230. The integrity of RNA was further confirmed after resolution by $1.0 \%$ agarose gel electrophoresis. Synthesis of cDNA was performed using the PrimeScript RT Reagent Kit with gDNA Eraser (Takara, Dalian, China) to remove genomic DNA, following the manufacturer's protocol.

\subsection{Expression Profiles}

Expression profiling of $\mathrm{ABC}$ transporters was evaluated using transcriptome data. To determine the expression patterns of $A B C$ transporter genes, the midgut, fat body, Malpighian tubule, ovary and testis of male and female, respectively, were harvested at the following developmental stages: egg; 1-day, 3-day, and 7-day-old larva; 1-day, 5-day, and 9-day-old pupa, as well as 1-day, 5-day, and 9-day-old male or female adults. Total RNA and cDNA preparation was performed as described above. The real-time quantitative PCR (RT-qPCR) was run on a CFX384 Real-time System (Bio-Rad, Singapore) using the NovoStar SYBR qPCR SuperMix (Novoprotein Scientific, Shanghai, China). The qRT-PCR program was run with the following conditions: $95^{\circ} \mathrm{C}$ for $2 \mathrm{~min}, 40$ cycles of $95^{\circ} \mathrm{C}$ for $15 \mathrm{~s}$, $60{ }^{\circ} \mathrm{C}$ for $30 \mathrm{~s}$, and $72{ }^{\circ} \mathrm{C}$ for $30 \mathrm{~s}$. A melting curve analysis at $60-95^{\circ} \mathrm{C}$ was performed to 
ensure the specificity of each primer. In addition, $\alpha$-tubulin and $\beta$-tubulin 1 [29] were used as reference genes for normalization. The primers used for ABC transporters validation were designed using Primer 3.0 (http:/ / bioinfo.ut.ee/primer3-0.4.0/) (Table S1). All reactions were undertaken with two technical replicates and three biological replicates. The relative expression level of the ABC genes was calculated using qBase [30].

\subsection{Insecticide Exposures}

The transcriptional responses of certain ABC genes of Z. cucurbitae to three commonly used insecticides were investigated, including one neonicotinoid, dinotefuran (98\% purity, Hailir, Shandong, China), one biogenic pesticide, abamectin (95\% purity, Bangnong, Guangdong, China), and one pyrethroid, $\beta$-cypermethrin (93\% purity, LIER-Chemical, Sichuan, China). Insecticides were dissolved in acetone, and then diluted to achieve five or six different concentrations: dinotefuran (at 1000, 700, 500, 250, $100 \mathrm{mg} / \mathrm{L}$ ), abamectin (at 120, 60, 30, 15, 7.5, $3.75 \mathrm{mg} / \mathrm{L}$ ) and $\beta$-cypermethrin (at 480, 240, 120, 80, $60 \mathrm{mg} / \mathrm{L}$ ). Newly emerged adults were collected and sexually separated in two cages. Five-day-old virgin female adults were anesthetized by exposure to $\mathrm{CO}_{2}$ for $2 \mathrm{~min}$ and then treated with insecticide $(0.5 \mu \mathrm{L}$ per fly) by dropping it onto their pronotum. For each concentration, approximately 20 adult flies were placed in a plastic cup. Z. cucurbitae were treated with acetone solutions as control. Each concentration of the insecticides was performed with three replicates. After $48 \mathrm{~h}$, the mortality of Z. cucurbitae was recorded. If the tested flies did not move after stimulation with a camel hairbrush, they were considered to be dead. The concentration producing either $50 \%$ or $30 \%$ lethality $\left(\mathrm{LC}_{50}\right.$ and $\mathrm{LC}_{30}$, respectively) was calculated using PoloPlus. Three insecticides, dinotefuran $\left(\mathrm{LC}_{50}, 296.01 \mathrm{mg} / \mathrm{L} ; \mathrm{LC}_{30}\right.$, $219.62 \mathrm{mg} / \mathrm{L})$, abamectin $\left(\mathrm{LC}_{50}, 14.66 \mathrm{mg} / \mathrm{L} ; \mathrm{LC}_{30}, 9.34 \mathrm{mg} / \mathrm{L}\right)$ and $\beta$-cypermethrin $\left(\mathrm{LC}_{50}\right.$, $\left.125.91 \mathrm{mg} / \mathrm{L} ; \mathrm{LC}_{30}, 100.58 \mathrm{mg} / \mathrm{L}\right)$ were used in this study. Insecticides were diluted in acetone at the experimentally-determined $\mathrm{LC}_{30}$ and $\mathrm{LC}_{50}$ concentrations. Using the same method (as above) to treat five-day-old virgin female adults, acetone was used as control. In total, 120 adults were treated with insecticides. Surviving flies after each treatment were randomly collected for RNA extraction at 12 h, $24 \mathrm{~h}$ and $48 \mathrm{~h}$ post-exposure. Four adults from each time points were collected and RNA extracted. There were four biological replicates for each treatment. Ribosomal protein subunit 3 and Ribosomal protein L13 were selected as reference genes evaluated before the quantification (Table S1).

\subsection{Statistical Analysis}

Relative gene expressions within tissues at each developmental stage were analyzed using SPSS 25.0 (SPSS Inc., Chicago, IL, USA). A $p<0.05$ was regarded as statistically significant.

\section{Results}

\subsection{Identification and Phylogenetic Analysis of ABC Transporter Genes}

Based upon the genome sequence, we identified 49 putative ABC genes in Z. cucurbitae. These genes were divided into eight subfamilies: seven $A B C A s$, seven $A B C B s, 10 A B C C s$, two $A B C D$ s, one $A B C E s$, three $A B C F s, 16 A B C G$ s, and three $A B C H s$ (Table 1), according to the highly conserved NBDs of $D$. melanogaster $\mathrm{ABC}$ transporter genes. All of the putative genes had complete ORFs. The 49 ABC transporters were retrieved using the NCBI protein database with its known homologous sequences. The NBD and TMD were further determined using the Pfam program to determine the 49 ABC transporters. Each potential $Z c A B C s$ is classified into two possible structural forms, full transporters (FTs) or half transporters (HFs). All of the ABCA subfamily belongs to FTs, ZcABCD, ZcABCG, and $\mathrm{ZcABCH}$ belong to HFs, and ZcABCG13 belongs to the FTs family. While some of the genes such as $Z c A B C B$ and $Z c A C C$ belong to FTs and the others belong to HFs. ZcABCA, $Z c A B C B, Z c A B C C$ and $Z c A B C D$ subfamilies contained both TMD and NBD organization, but $Z c A B C G$ and $Z c A B C H$ subfamilies formed NBD-TMD organization. However, no TMD motif was predicted for the $Z c A B C E s$ and $Z c A B C F s$ subfamilies. 
Table 1. Characterization of $49 \mathrm{ABC}$ transporter proteins in Zeugodacus cucurbitae.

\begin{tabular}{|c|c|c|c|c|c|c|}
\hline Subfamily & Gene & Gene IDc & Length (AA) & Topology ${ }^{a}$ & N-Glc ${ }^{b}$ & O-Glc ${ }^{c}$ \\
\hline $\mathrm{A}$ & $Z c A B C A 1$ & LOC105218935 & 1768 & $(5 / 7 \mathrm{TMD}-\mathrm{NBD})_{2}$ & 14 & 13 \\
\hline A & $Z_{c} A B C A 2$ & LOC105214217 & 1210 & $(6 \mathrm{TMD}-\mathrm{NBD})_{2}$ & 8 & 1 \\
\hline A & $Z c A B C A 3$ & LOC105214171 & 458 & NBD & 1 & 1 \\
\hline $\mathrm{A}$ & $Z c A B C A 4$ & LOC105214218 & 1685 & $(7 / 6 \mathrm{TMD}-\mathrm{NBD})_{2}$ & 11 & 6 \\
\hline $\mathrm{A}$ & $\mathrm{ZcABCA5}$ & LOC105210581 & 1610 & $(7 / 6 \mathrm{TMD}-\mathrm{NBD})_{2}$ & 3 & 15 \\
\hline $\mathrm{A}$ & $Z c A B C A 6$ & LOC105219391 & 1568 & $(6 \mathrm{TMD}-\mathrm{NBD})_{2}$ & 9 & 15 \\
\hline A & $Z c A B C A 7$ & LOC105215594 & 1957 & $(6 / 7 \mathrm{TMD}-\mathrm{NBD})_{2}$ & 12 & 6 \\
\hline $\mathrm{B}$ & $Z_{c} A B C B 1$ & LOC105218240 & 850 & 11TMD-NBD & 7 & 1 \\
\hline $\mathrm{B}$ & $Z c A B C B 2$ & LOC105221102 & 719 & 6TMD-NBD & 5 & 4 \\
\hline $\mathrm{B}$ & $Z_{c} A B C B 3$ & LOC105218701 & 732 & 3TMD-NBD & 3 & 9 \\
\hline $\mathrm{B}$ & $Z_{c} A B C B 4$ & LOC105217120 & 673 & 11TMD-NBD & 6 & 2 \\
\hline $\mathrm{B}$ & $\mathrm{ZcABCB5}$ & LOC105213990 & 1295 & $(6 / 5 \mathrm{TMD}-\mathrm{NBD})_{2}$ & 3 & 9 \\
\hline $\mathrm{B}$ & $Z_{c} A B C B 6$ & LOC105212618 & 1296 & $(7 / 6 \mathrm{TMD}-\mathrm{NBD})_{2}$ & 7 & 7 \\
\hline $\mathrm{B}$ & $Z c A B C B 7$ & LOC105212186 & 1302 & $(6 / 5 \mathrm{TMD}-\mathrm{NBD})_{2}$ & 9 & 4 \\
\hline $\mathrm{C}$ & $Z_{c} A B C C 1$ & LOC105214114 & 1352 & $(6 / 5 \mathrm{TMD}-\mathrm{NBD})_{2}$ & 4 & 4 \\
\hline $\mathrm{C}$ & $Z_{c} A B C C 2$ & LOC105214112 & 1353 & $(7 / 5 \mathrm{TMD}-\mathrm{NBD})_{2}$ & 9 & 4 \\
\hline $\mathrm{C}$ & $Z_{c} A B C C 3$ & LOC105214120 & 1346 & $(7 / 5 \mathrm{TMD}-\mathrm{NBD})_{2}$ & 7 & 5 \\
\hline $\mathrm{C}$ & $Z c A B C C 4$ & LOC105214115 & 1365 & $(7 / 5 \mathrm{TMD}-\mathrm{NBD})_{2}$ & 5 & 11 \\
\hline $\mathrm{C}$ & $\mathrm{ZcABCC5}$ & LOC105209430 & 1358 & $(4 / 5 \mathrm{TMD}-\mathrm{NBD})_{2}$ & 9 & 8 \\
\hline $\mathrm{C}$ & $Z c A B C C 6$ & LOC105214620 & 1295 & $(3 / 4 T M D-N B D)_{2}$ & 12 & 8 \\
\hline $\mathrm{C}$ & $Z c A B C C 7$ & LOC105217830 & 1408 & $(6 / 5 \mathrm{TMD}-\mathrm{NBD})_{2}$ & 5 & 5 \\
\hline $\mathrm{C}$ & $Z_{c} A B C C 8$ & LOC105218206 & 1552 & 7TMD-(5TMD-NBD) $)_{2}$ & 7 & 4 \\
\hline $\mathrm{C}$ & $Z c A B C C 9$ & LOC105210838 & 1494 & 5TMD-(6TMD-NBD) $)_{2}$ & 10 & 1 \\
\hline $\mathrm{C}$ & $Z_{c} A B C C 10$ & LOC105217701 & 1313 & 4TMD-NBD & 15 & 59 \\
\hline $\mathrm{D}$ & $Z c A B C D 1$ & LOC105218326 & 737 & 4TMD-NBD & 2 & 2 \\
\hline $\mathrm{D}$ & $Z_{c} A B C D 2$ & LOC105208882 & 658 & 3TMD-NBD & 4 & 6 \\
\hline $\mathrm{E}$ & $Z c A B C E 1$ & LOC105221159 & 611 & NBD-NBD & 1 & 6 \\
\hline $\mathrm{F}$ & $Z_{c A B C F 1}$ & LOC105212708 & 897 & NBD-NBD & 8 & 22 \\
\hline $\mathrm{F}$ & $Z_{c} A B C F 2$ & LOC105216261 & 613 & NBD-NBD & 4 & 8 \\
\hline $\mathrm{F}$ & $Z c A B C F 3$ & LOC105208450 & 708 & NBD-NBD & 4 & 8 \\
\hline G & ZcABCG1 & LOC105220708 & 607 & NBD-7TMD & 3 & 9 \\
\hline G & $\mathrm{ZcABCG} 2$ & LOC105220707 & 891 & NBD-7TMD & 7 & 36 \\
\hline G & $Z_{c} A B C G 3$ & LOC105215537 & 679 & NBD-5TMD & 4 & 21 \\
\hline G & $Z_{c} A B C G 4$ & LOC105209688 & 1124 & NBD-5TMD & 9 & 85 \\
\hline G & ZcABCG5 & LOC105217559 & 666 & NBD-7TMD & 2 & 7 \\
\hline G & ZcABCG6 & LOC105215923 & 641 & NBD-7TMD & 3 & 12 \\
\hline G & ZcABCG7 & LOC105209629 & 638 & NBD-7TMD & 6 & 15 \\
\hline G & ZcABCG8 & LOC105209627 & 724 & NBD-6TMD & 2 & 0 \\
\hline G & ZcABCG9 & LOC105218359 & 615 & NBD-5TMD & 4 & 6 \\
\hline G & ZcABCG10 & LOC105213062 & 688 & NBD-6TMD & 3 & 0 \\
\hline G & ZcABCG11 & LOC105209626 & 806 & NBD-6TMD & 5 & 46 \\
\hline G & ZcABCG12 & LOC105217960 & 619 & NBD-6TMD & 6 & 6 \\
\hline G & ZcABCG13 & LOC105217961 & 1388 & NBD-5TMD-NBD-8TMD & 9 & 26 \\
\hline G & ZcABCG14 & LOC105213059 & 862 & NBD-7TMD & 7 & 31 \\
\hline G & ZcABCG15 & LOC105213060 & 730 & NBD-6TMD & 7 & 2 \\
\hline G & ZcABCG16 & LOC105212186 & 743 & NBD-5TMD & 4 & 28 \\
\hline $\mathrm{H}$ & $\mathrm{ZcABCH1}$ & LOC105217189 & 775 & NBD-7TMD & 10 & 15 \\
\hline $\mathrm{H}$ & $\mathrm{ZcABCH} 2$ & LOC105217218 & 764 & NBD-7TMD & 10 & 12 \\
\hline $\mathrm{H}$ & $\mathrm{ZcABCH}$ & LOC105218730 & 725 & NBD-7TMD & 4 & 9 \\
\hline
\end{tabular}

${ }^{a}$ Transmembrane helices (TMs) were predicted using the TMHMM 2.0 server. ${ }^{b} \mathrm{~A} N$-glycosylation sites were predicted using NetNGlyc 1.0 server; only N-glycosylation site with a "potential" score $>0.5$ and with a jury agreement were considered. c O-glycosylation sites were predicted using NetOGlyc 4.0 server. If the G-score was higher than 0.5 the residue was considered to be O-glycosylated, the total number of O-glycosylated sites (glycosylated serine and threonine) is shown.

To determine the homology and phylogenetic relationships, $49 \mathrm{ABC}$ transporter proteins were derived from the NCBI Nt database. A phylogenetic tree was constructed based upon presence of ZcABC transporter proteins and DmABC transporter proteins using NDBs domains. Phylogenetic analysis indicated that melon fly ABC transporters can 
be divided into eight subfamilies (listed A-H) (Figure 1). Phylogenetic analysis revealed that $Z c A B C s$ were highly similar to $D m A B C s$, with the same subfamily clustered on the same branches.

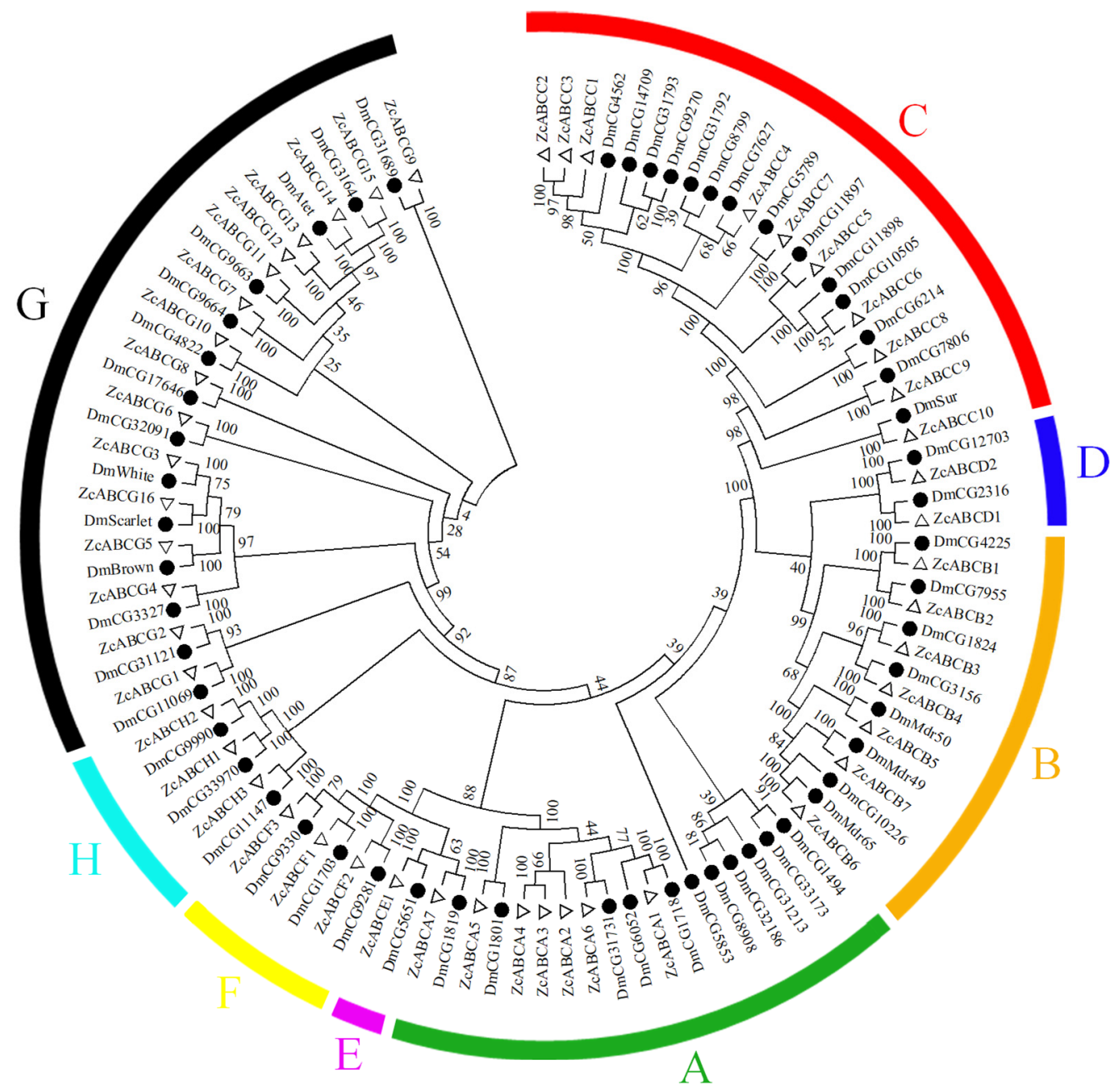

Figure 1. Phylogenetic analysis of $\mathrm{ABC}$ transporters in Zeugodacus cucurbitae. The phylogenetic tree was constructed by ClustalW alignment using the nucleotide binding domains (NBDs) of ABC transporters from Z. cucurbitae and Drosophila melanogaster. The number at the branch point of the bootstrap level was from 1000 replications with MEGA 7.0 using the maximum-likelihood method. The hollow diamond and solid circle represent different $\mathrm{ABC}$ proteins from Z. cucurbitae and D. melanogaster, respectively. Capital letters $\mathbf{A}-\mathbf{H}$ with different colors indicate the different subfamilies of $\mathrm{ABC}$ transporters.

\subsection{The Expression Pattern of ZcABCs}

The expressions of 49 ABC transporter genes across developmental stages and tissues in Z. cucurbitae adults with RPKM > 0 were analyzed. Regarding developmental stages, the majority of $Z c A B C$ s were expressed at low levels in egg and larva stages. We detected multiple Z. cucurbitae ABC genes that are highly expressed during the pupation and adult stage. The analysis revealed that the expression of eight $\mathrm{ABC}$ genes and nine $\mathrm{ABC}$ genes were expressed in increasing amounts as the female adult and the male adult developed, respectively. Some ABC genes are highly expressed in one day pupa (Figure 2). 


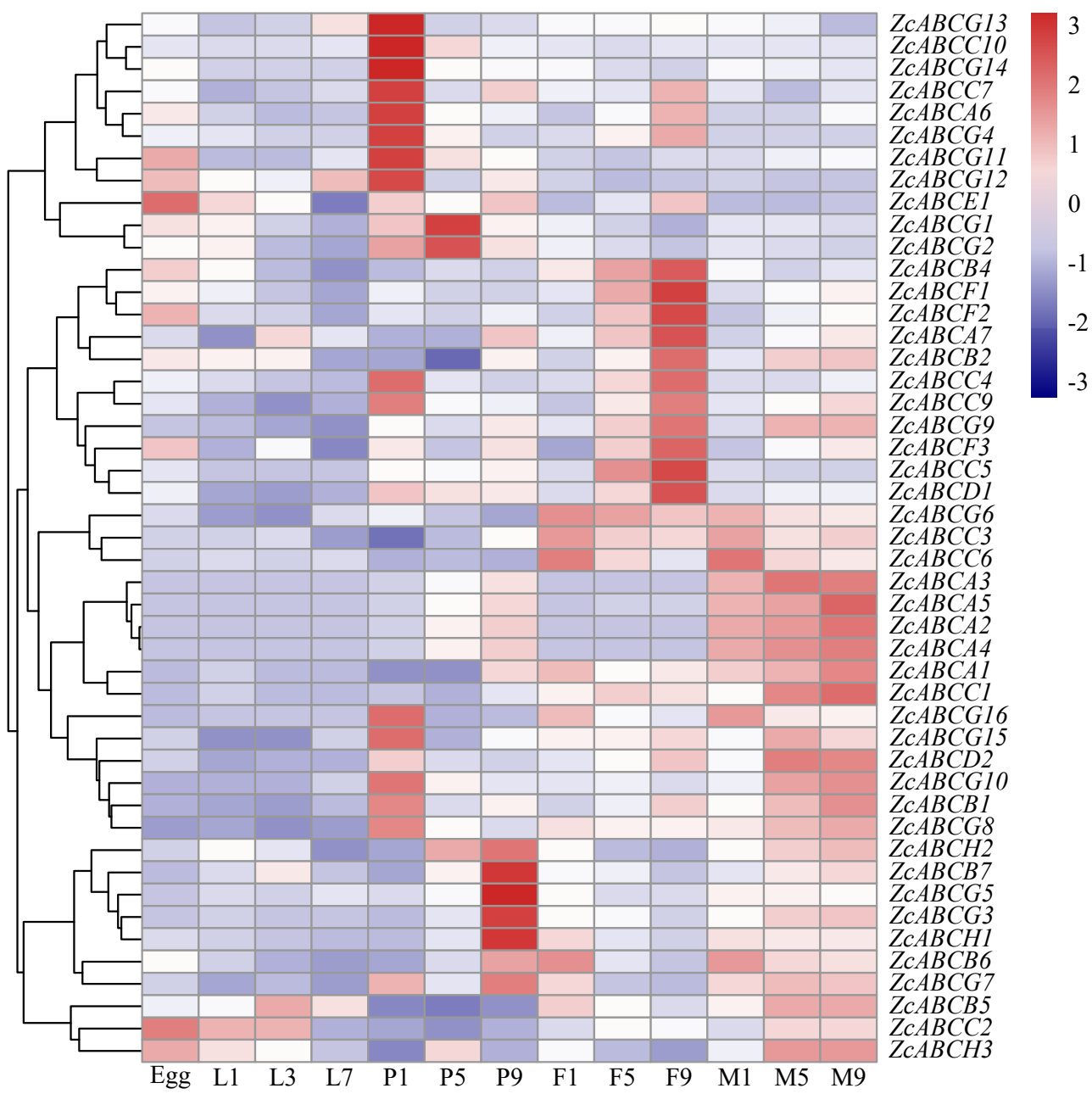

Figure 2. Expression profiles of ABC transporters at different development stages of Zeugodacus cucurbitae. Letters on the right are the gene names. The mRNA levels, represented by normalized $\log _{2}($ FPKM +1$)$ values, are shown in the gradient heat map with colors ranging from blue (low expression) to red (high expression). L1, 1-day-old larva, L3, 3-day-old larva, L7, 7-day-old larva. In the same way, $\mathrm{P}$ represents pupa, $\mathrm{F}$ represents female adult and $\mathrm{M}$ represents male adult, the number represents the day.

Moreover, we evaluated the levels of $49 \mathrm{ZcABCs}$ transporters genes in different tissues. More than half of the Z. cucurbitae ABC genes were expressed in Malpighian tubule and midgut (Figure 3). Some tissue-specific $A B C$ genes were identified, e.g., $Z c A B C A 2$, $Z c A B C A 3, Z c A B C A 4$, and ZcABCA5 in the testis, and ZcABCA6, ZcABCB4, ZcABCE1, $Z c A B C F 2$ in the ovary. Some of these genes corresponded to the high expression at adult stage.

\subsection{Transcriptional Responses of $\mathrm{ZcABCs}$ to Insecticides Exposures}

In order to evaluate the relative expression of $Z c A B C B s$ and $Z c A B C C s$ in response to insecticides exposures, five-day-old female adults were firstly treated with different insecticides and the levels of mortality quantified. The $\mathrm{LC}_{50}$ values of the insecticides for dinotefuran, abamectin and $\beta$-cypermethrin were $296.010 \mathrm{mg} / \mathrm{L}, 14.658 \mathrm{mg} / \mathrm{L}$, and $125.908 \mathrm{mg} / \mathrm{L}$, respectively (Table 2). The $95 \%$ confidence intervals of the $\mathrm{LC}_{30}$ and $\mathrm{LC}_{50}$ values for these insecticides were also calculated.

The dosage of $\mathrm{LC}_{30}$ and $\mathrm{LC}_{50}$ insecticides were thereafter used to evaluate the induction of gene expression of $A B C$ genes. The results showed that only $Z c A B C B 7$ and $Z c A B C C 2$, among 17 selected genes that are mainly involved in detoxification metabolism, were remarkably over-expressed in Z. cucurbitae when challenged by a $\mathrm{LC}_{30}$ of these three 
insecticides (Figure 4). For $\beta$-cypermethrin, ZcABCB1, ZcABCB6, ZcABCB7, ZcABCC2, $Z c A B C C 3, Z c A B C C 4, Z c A B C C 5$, and $Z c A B C C 7$ were significantly up-regulated $24 \mathrm{~h}$ after a $L_{30}$ dosage. $Z c A B C B 2, Z c A B C C 1$, and $Z c A B C C 6$ were significantly down-regulated by the $L_{30}$ dosage, and $Z c A B C B 3$ and $Z c A B C B 4$ significantly down-regulated after 48 h (Figure $4 \mathrm{~A}$ ). After exposure to abamectin, ZcABCB2, ZcABCB7, ZcABCC2, ZcABCC3, $Z c A B C C 4, Z c A B C C 5, Z c A B C C 7$, and $Z c A B C C 9$ were significantly up-regulated $12 \mathrm{~h}$ after dosage with the $\mathrm{LC}_{30}$. The mRNA expression levels were up-regulated from 1- to 2.5fold. ZcABCB1, ZcABCB4, ZcABCB6, ZcABCC1, ZcABCC2, ZcABCC3, ZcABCC4, ZcABCC5, and $Z c A B C C 6$ were all significantly down-regulated $24 \mathrm{~h}$ and $48 \mathrm{~h}$ after a $\mathrm{LC}_{50}$ dosage (Figure $4 \mathrm{~B}$ ). After a challenge with dinotefuran, only the expression of $Z c A B C B 7$ was significantly up-regulated $12 \mathrm{~h}$ after a $L_{30}$ dosage. $Z c A B C C 1, Z c A B C C 2$, and $Z c A B C C 10$ were significantly up-regulated $48 \mathrm{~h}$ after a $\mathrm{LC}_{30}$ and $24 \mathrm{~h}$ after $\mathrm{LC}_{50}$ treatments (Figure $4 \mathrm{C}$ ).

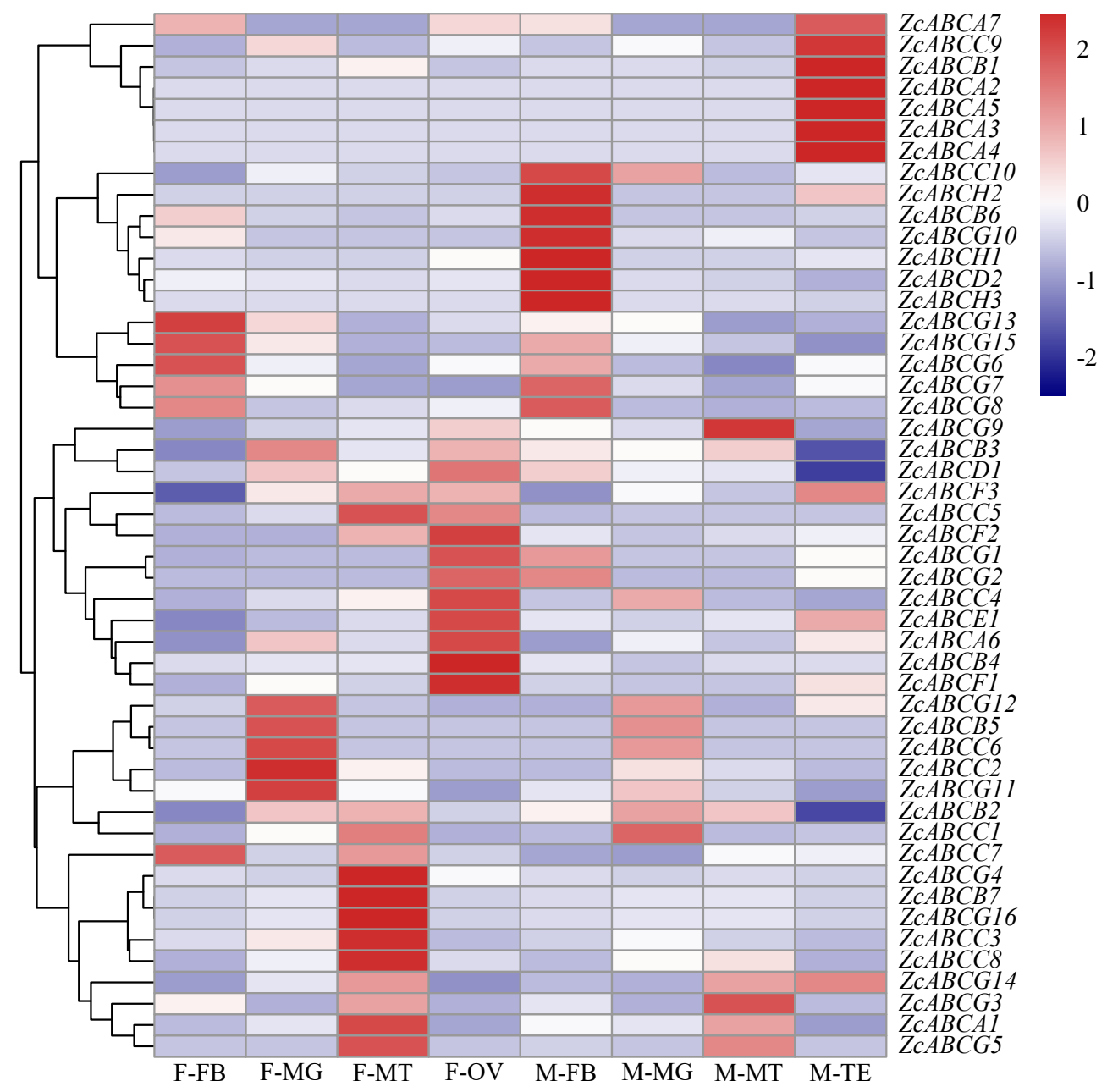

Figure 3. Expression profiles of $\mathrm{ABC}$ transporter genes in different tissues of Zeugodacus cucurbitae. The relative expression of each gene was normalized using $\log _{2}(\mathrm{FPKM}+1)$, and shown in the gradient heat map with colors. FB, fat body, MG, Malpighian tubule, MT, midgut, OV, ovary, and TE, testis. F represents female adult and $\mathrm{M}$ represents male adult.

Table 2. Toxicity bioassay of three insecticides against Zeugodacus cucurbitae.

\begin{tabular}{|c|c|c|c|c|c|c|c|}
\hline Insecticides & $n$ & Slope $( \pm$ SE $)$ & $\mathrm{LC}_{30}(\mathrm{mg} / \mathrm{L})$ & $95 \% \mathrm{CI}^{\mathrm{a}}$ & $\mathrm{LC}_{50}(\mathrm{mg} / \mathrm{L})$ & $95 \% \mathrm{CI}$ & $\chi^{2 b}$ \\
\hline$\beta$-Cypermethrin & 300 & $5.376 \pm 0.541$ & 100.580 & 91.336-109.824 & 125.908 & $115.291-138.841$ & 0.443 \\
\hline Abamectin & 360 & $2.682 \pm 0.234$ & 9.344 & $6.734-11.963$ & 14.658 & $11.405-18.723$ & 5.1793 \\
\hline Dinotefuran & 331 & $4.045 \pm 0.375$ & 219.616 & 118.042-296.924 & 296.010 & 196.121-398.702 & 8.8061 \\
\hline
\end{tabular}

${ }^{\mathrm{a}} \mathrm{CI}$ means confidence interval. ${ }^{\mathrm{b}} \chi^{2}$ value for goodness of fit test. 
A

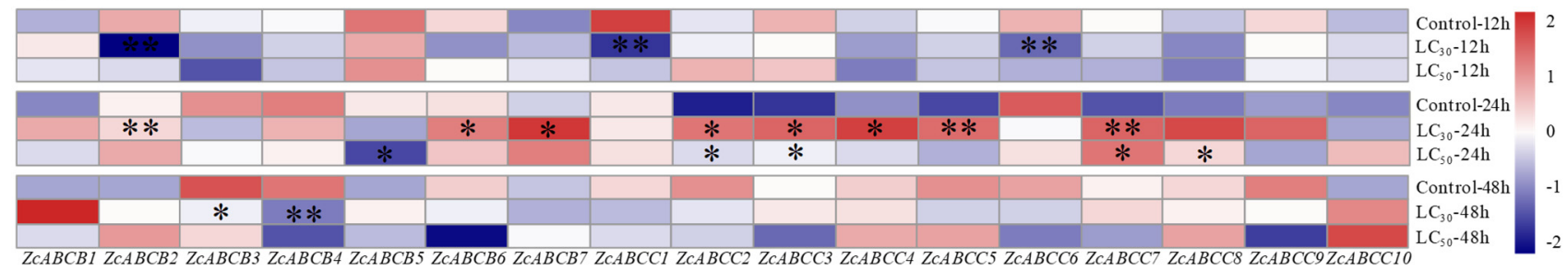

B

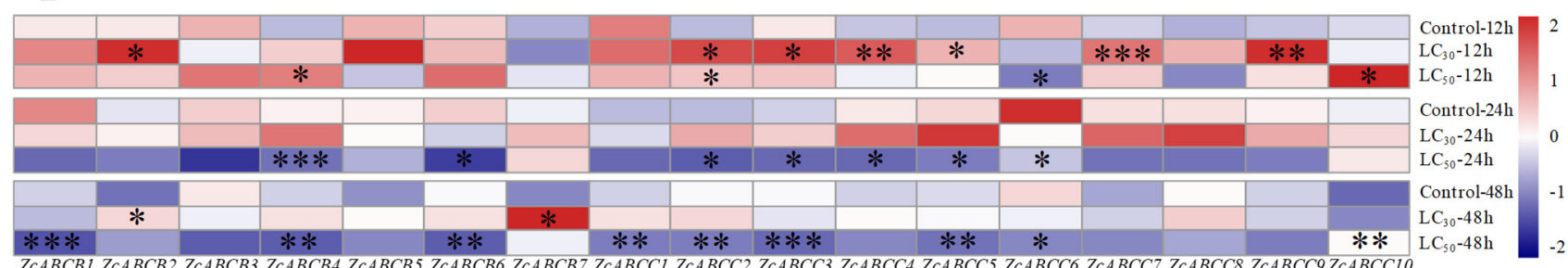

ZcABCB1 ZcABCB2 ZcABCB3 ZcABCB4 ZcABCB5 ZcABCB6 ZcABCB7 ZcABCC1 ZcABCC2 ZcABCC3 ZcABCC4 ZcABCC5 ZcABCC6 ZcABCC7 ZcABCC8 ZcABCC9 ZcABCC10

$\mathrm{C}$

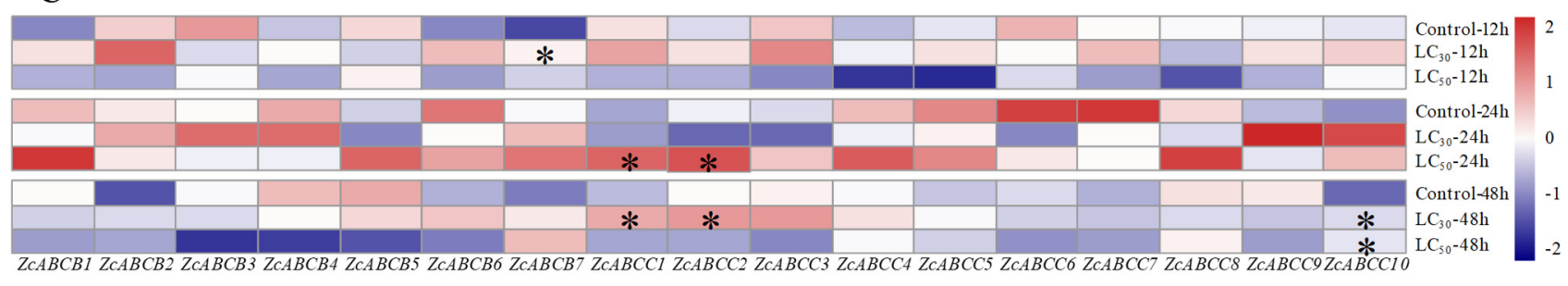

Figure 4. Relative expression levels of 17 ABC transporters in Zeugodacus cucurbitae treated with $\beta$-cypermethrin (A), abamectin (B) and dinotefuran (C). The relative expression of each gene challenged by three insecticides was determined by qRT-PCR. Blue indicates low expression, and red indicates high expression. Student's $t$-test was performed for comparison with the corresponding control group, ${ }^{*} p<0.05,{ }^{* *} p<0.01,{ }^{* * *} p<0.001$.

\subsection{Transcriptional Response of $Z c A B C$ s to $\beta$-Cypermethrin Exposure in Tissues}

Expression levels of ZcABCB1, ZcABCB6, ZcABCB7, ZcABCC2, ZcABCC3, ZcABCC4, $Z c A B C C 5$, and $Z c A B C C 7$ within several tissues important for detoxification (midgut, fat body, and Malpighian tubules) were quantified at $12 \mathrm{~h}$ and $24 \mathrm{~h}$ after a $\mathrm{LC}_{30}$ exposure to $\beta$-cypermethrin. All of these $A B C$ transporter genes were significantly induced within the fat body $24 \mathrm{~h}$ after exposure (Figure 5), especially $Z c A B C B 7$ and $Z c A B C C 2$ with a 4.25 and 3.30-fold change, respectively (Figure 5C,D). In addition, $Z c A B C B 7, Z c A B C C 2, Z c A B C C 3$, $Z c A B C C 4$, and $Z c A B C C 7$ were significantly down-regulated in Malpighian tubules $12 \mathrm{~h}$ after exposure. The 17 genes showed no significant expression changes within the midgut, although $Z c A B C B 7, Z c A B C C 3, Z c A B C C 4$, and $Z c A B C C 7$ were down-regulated markedly after both $12 \mathrm{~h}$ and $24 \mathrm{~h}$. 

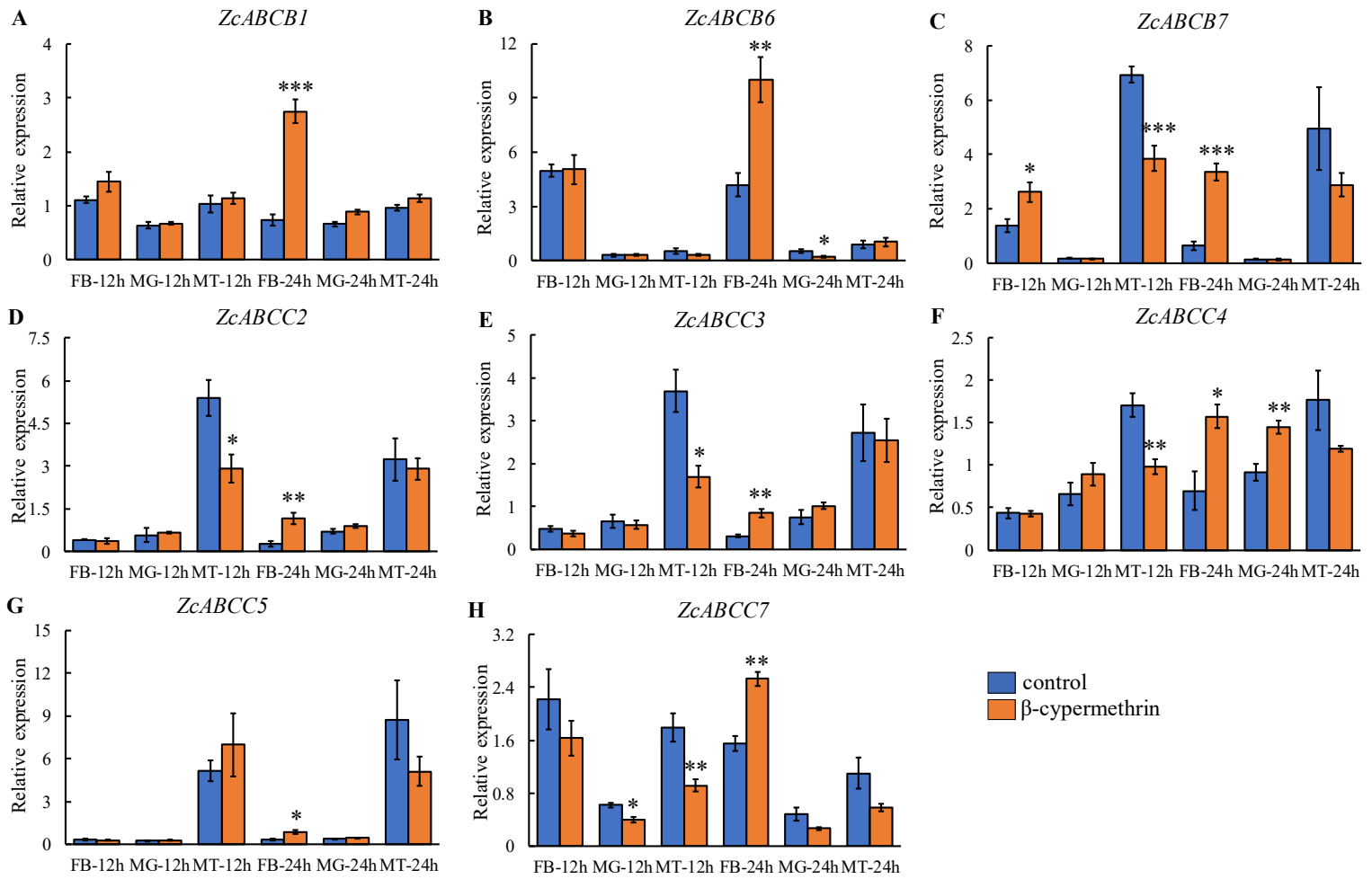

Figure 5. Expression of $Z c A B C B 1$ (A), ZcABCB6 (B), ZcABCB7 (C), ZcABCC2 (D), ZcABCC3 (E), ZcABCC4 (F), ZcABCC5 (G) and $Z c A B C C 7(\mathbf{H})$ in three tissues of Zeugodacus cucurbitae at $12 \mathrm{~h}$ and $24 \mathrm{~h}$ after exposure to a $\mathrm{LC}_{30}$ of $\beta$-cypermethrin. Student's $t$-tests were performed for comparison with the corresponding control group, ${ }^{*} p<0.05,{ }^{* *} p<0.01,{ }^{* * *} p<0.001$.

\section{Discussion}

With the relatively recent improvements in sequencing technology, more genomes of arthropods have been sequenced and annotated, leading to an expansion of databases and ability to identify family genes. For example, there are $56 \mathrm{ABC}$ transporter genes in D. melanogaster [31], 55 in B. tabaci [32], 55 in Bombyx mori, 73 in Tribolium castaneum, 41 in Apis mellifera, 52 in Anopheles gambiae [33], and 44 in Diaphorina citri [34]. In this study, a total of $49 \mathrm{ABC}$ transporter genes were identified in Z. cucurbitae based upon the sequenced genome. These genes were divided into eight subfamilies (ABCA-ABCH) which varied based upon their functions and similarity of conserved domains. Compared to $D$. melanogaster, the A and C subfamily of Z. cucurbitae have relatively small numbers. The Z. cucurbitae ABCA subfamily has six FT and one incomplete ABC protein with one NBD domain. In silkworm, ABCAs consist of two FT, one HT, and only three have one NBD [35]. In Bactrocera dorsalis, $\mathrm{ABCAs}$ consist of five FT and two HT [36]. In contrast, all of the ABCAs subfamily genes were FTs in A. gambia [12].

The structural differences between the $\mathrm{ABCA}$ subfamily indicate diversity associated with the evolutionary process in insects. The analysis of the $A B C B$ subfamily of $Z$ cucurbitae revealed three FT and four HT members. This differs from that of $B$. tabaci in which all ABCBs members are HTs. Both FTs and HTs play important roles in arthropods [37]. For the $\mathrm{ABCD}, \mathrm{ABCE}, \mathrm{ABCF}$, and $\mathrm{ABCH}$ subfamilies of $Z$ cucurbitae, two, one, three, and three proteins were identified, respectively. The same numbers of these subfamily genes were also identified in other insects, indicative of a conserved evolution.

The ABCG genes constitute the largest subfamily, and the $\mathrm{ABCH}$ subfamily is similar to ABCG. ABCGs are involved in pigment precursor transporters, such as brown, scarlet and white genes in D. melanogaster [31,38]. The $\mathrm{ABCH}$ subfamily was first reported in $D$. melanogaster but has not been found in plant and fungi [32]. Hence, these genes may play unique roles in insects. In Locusta migratoria an $\mathrm{ABCH}$ subfamily member $L m A B C H-9_{c}$ was 
demonstrated to be involved in the process of constructing a lipid-based barrier on the cuticle surface [39].

A comprehensive expression pattern of $Z c A B C$ genes could provide an insight into potential physiological functions associated with development and/or within tissues. In $Z$. cucurbitae, $Z c A B C s$ were expressed in the larva stage at a relatively low level but with a high expression in egg, pupa, and adult stages. This indicated that most of $Z c A B C s$ are involved in metamorphosis development. This is supported by a study of a knockdown of the TcABCA-9A/9B in T. castaneum, as this caused wing defects and elytral shortening at pupa and adult, and knockdown of TCABCE-3A and TCABCF-2A was lethal because of failed molting [40]. In $Z$ cucurbitae, five $Z c A B C A$ genes exhibited a higher expression at male adult stage that increased gradually, which is consistent with results in Helicoverpa armigera [41].

Expression of $Z c A B C B s$ and $Z c A B C C s$ family genes were dynamic at all developmental stages of $Z$ cucurbitae. The expression patterns were different among these genes, indicating that $A B C B$ and $A B C C$ subfamilies probably have minor roles during insect metamorphosis. $A B C B$ and $A B C C$ subfamilies are also thought to be involved in pesticide resistance and other chemicals in insects. ZcABCE1, ZcABCF2, and ZcABCF3 were highly expressed at each stage. Hence, the expression patterns of these three genes are consistent with basic functions of biogenesis and translation regulation of ribosomes [42]. ZcABCGs and $\mathrm{ZcABCHs}$ were expressed in a complex fashion at all developmental stages, because of their functional diversity.

The expressions of $Z c A B C s$ were diverse within the different tissues. Multiple $Z c A B C B s$ and $Z c A B C C s$ were highly expressed in the Malpighian tubule and midgut, such as $Z c A B C C$ $(1-6,8), Z c A B C B(2,3,5,7)$, and $Z c A B C G(3,5,9,11,16)$. Furthermore, the midgut and the Malpighian tubule are a digestive organ and excretory organ, respectively, and are involved in detoxification metabolism. The expression patterns of these genes are similar to most of those from metabolic detoxification families, such as P450, glutathione S-transferase, and carboxylesterase [1]. For example, a knockout of three ABCC subfamily genes (Mdr49, Mdr50, and Mdr65) in D. melanogaster [43], and Mdr49, Mdr50, and Mdr65 resulted in an increased susceptibility to insecticide. In P. xylostella, it has been demonstrated that the $p x A B C C 2$ and $p x A B C C 3$ proteins also functioned as receptors for BtCry1 toxins within the midgut [44]. These comparable studies provide insights into the potential function of these highly expressed $A B C$ genes within the midgut and Malpighian tubule. The expression of the $Z c A B C$ gene within the fat body suggested its potential function in the transport of cuticular lipids. In T. castaneum, an ABC transporter gene plays an important role in cuticle lipid transport to maintain osmotic balance [40]. In this study, some ZcABCs were highly expressed within reproductive tissues. Furthermore, these genes were also expressed in increasing levels as the adult developed. The presence and expression of these genes within testis or ovary indicates that they could play a role in spermatic or ovarian development, respectively.

In addition to the transport of insecticides and allelochemicals, $\mathrm{ABC}$ transporters have also been studied as insecticide targets. $\mathrm{ABC}$ transporters were involved in the degradation of plant secondary metabolites in the cotton bollworm, H. armigera [5]. ABCBs are often positively correlated with field population resistance and ABCB FTs have been associated with insecticide transport and/or resistance in insects [4]. The ABCC subfamily known as MRPs, transports a range of substrates, such as drugs, endogenous compounds and glutathione, and cyclic nucleotides [16]. In Anopheles arabiensis and D. melanogaster, $A B C B$ and $A B C C$ genes were overexpressed in a dichlorodiphenyltrichloroethane (DDT)-resistant strain $[45,46]$. Hence, $B$ and $C$ subfamilies were selected for further analysis of the transcriptional response to the insecticides (dinotefuran, abamectin and $\beta$-cypermethrin) in this study. An analysis of the expression of the 17 candidate $A B C$ genes was undertaken after insecticide exposure. The results showed that some of ZcABCBs and ZcABCCs were highly expressed after treatment with the insecticides. This positive correlation between induction of the $\mathrm{ABC}$ subfamily and insecticide resistance has also been demonstrated 
in other insects [16]. After insecticide treatment, the $A B C$ gene showed up-regulation in several insects [1]. For example, a CRISPR-Cas9 knockout for $M d r 65$ was more susceptible to all neuroactive insecticides tested [43]. When imidacloprid was used to treat $B$. tabaci adults, the expression of $A B C G 3$ was increased, and a knockdown of $A B C G 3$ significantly increased the mortality of adults exposed to imidacloprid [13]. In B. dorsalis, after insecticides exposure, more than $10 \mathrm{ABC}$ genes were significantly overexpressed [36]. Two ABC transporters, $Z c A B C B 7$ and $Z c A B C C 2$, were significantly up-regulated in Z. cucurbitae after exposure to a $\mathrm{LC}_{30}$ of three insecticides.

To assess xenobiotic responses, three insecticides were selected, namely, abamectin, $\beta$ cypermethrin and dinotefuran. We found that most of the $Z c A B C B$ and $Z c A B C C$ subfamily genes showed no response to dinotefuran. This may result from that neonicotinoid insecticides are more effective to Hemiptera [16,34,47]. However, ZcABCB7, ZcABCC2, ZcABCC3, $Z c A B C C 4, Z c A B C C 5$, and $Z c A B C C 7$ were all significantly up-regulated by abamectin and $\beta$ cypermethrin exposure. Similar results were found in B. dorsalis [36]. A knockdown of $B d A B C B 7$ significantly increased the toxicity of malathion, and increased the mortality of $B$. dorsalis [36]. After exposure to $\beta$-cypermethrin, many $A B C B$ s and $A B C C$ s were up-regulated at $24 \mathrm{~h}$, a time point consistent with in other literatures. However, after exposure to abamectin, most of these genes were up-regulated at $12 \mathrm{~h}$, rather than $24 \mathrm{~h}$. Furthermore, the majority of $\mathrm{ABCBs}$ and $\mathrm{ABCC}$ had no response to dinotefuran exposure. Therefore, we used $\beta$-cypermethrin to test which tissues might play a role in detoxification metabolism After treatment of $Z$ cucurbitae adults with a $\mathrm{LC}_{30}$ of $\beta$-cypermethrin, the midgut, Malpighian tubule, and fat body were dissected $12 \mathrm{~h}$ and $24 \mathrm{~h}$ after insecticide exposure. The genes: ZcABCB1, ZcABCB6, ZcABCB7, ZcABCC2, ZcABCC3, ZcABCC4, $Z c A B C C 5$, and $Z c A B C C 7$ were specifically induced within the fat body $24 \mathrm{~h}$ after exposure. This result is consistent with the expression pattern of adults after $\beta$-cypermethrin exposure, indicating a detoxification related role of these genes in Z. cucurbitae. However, further research is required to fully elucidate this response and its mechanism of action.

Among the seven $\mathrm{ABCB}$ transporters identified in Z. cucurbitae, three of them were FTs, and could be participating in detoxification metabolism. In D. melanogaster, three genes ( $m d r 49, m d r 50$, and $m d r 65)$ are part of the ABCB transporters, and disruption of the $m d r 49$ can increase resistance to colchicine [48]. Furthermore, knockout of these three genes renders flies more susceptible to nitenpyram and imidacloprid [43]. A number of invesigations have suggested that these gene products are involved in the transport of these chemicals [49]. In this study, ZcABCB7, which is homologous with $m d r 49$, was mainly expressed in the midgut, fat body and Malpighian tube. The upregulation of $Z c A B C B 7$ in $Z$. cucurbitae by three insecticides exposure indicated an insecticide metabolism related role in Z. cucurbitae.

In addition to the participation of $A B C B$ transporters in insecticide detoxification, $A B C C$ transporters were also found to be involved in insecticide metabolism. A total of 10 $Z c A B C C$ s were identified in Z. cucurbitae. They are FTs and may have various functions in ion transport, cell-surface receptor activity and substrate translocation [50]. In humans, the ABCCs mainly comprise MRPs [3]. In Manduca sexta, ABCC transporters are involved in multidrug resistance and detoxification [51]. In Chilo suppressalis, CsABCC8 was significantly up-regulated after chlorantraniliprole exposure and CsABCC 8 was homologous with the sulfonylurea receptor (Sur) that may participate in insecticide metabolism [52]. In this study, ZcABCC2 and ZcABCC3 were mainly expressed in adults and within the Malpighian tube. The significant up-regulation of these genes after exposure to three insecticides indicate that they may be involved in insecticide metabolism in Z. cucurbitae.

\section{Conclusions}

In summary, herein, a total of $49 \mathrm{ABC}$ transporter genes were identified from $Z$. cucurbitae. All of these genes had complete ORFs and fitted to a genome scaffold. The phylogenetic relation and subfamily classifications were determined based on the presence of clear homologous orthologs in D. melanogaster. A bioassay that assessed responses to three 
kinds of insecticides was performed in Z. cucurbitae, and the $\mathrm{LC}_{50}$ dosage of $\beta$-cypermethrin, abamectin and dinotefuran quantified as 125.908, 14.658, and $296.010 \mathrm{mg} / \mathrm{mL}$, respectively. Two prominent subfamily members, ABCB and ABCC, were selected for the evaluation of these three insecticides, with results that indicated that $Z c A B C B 7$ and $Z c A B C C 2$ may be associated with insecticide tolerance. Dissected tissues from flies exposed to $\beta$-cypermethrin, revealed that the $Z c A B C B 1, Z c A B C B 6, Z c A B C B 7, Z c A B C C 2, Z c A B C C 3, Z c A B C C 4, Z c A B C C 5$, and $Z c A B C C 7$ genes were significantly expressed in the fat body, implying that the fat body may be the major tissue to transport pyrethroids.

Supplementary Materials: The following are available online at https:/ / www.mdpi.com/2075-445 0/12/3/270/s1, Table S1. Primers for the ABC transporter genes for RT-qPCR.

Author Contributions: D.W. and J.-J.W. designed the experiments. H.-Q.X., M.M. and Y.-P.M. contributed the materials and performed the experiments; H.-Q.X., S.-Y.Z. and W.-J.L. analyzed the data; H.-Q.X., D.W. and J.-J.W. wrote the paper. All authors have read and agreed to the published version of the manuscript.

Funding: This study was supported in part by the earmarked fund for the Modern Agro-industry (Citrus) Technology Research System of China (CARS-27), the Chongqing Research Program of Basic Research and Frontier Technology (CSTC2016jcyjA0019).

Institutional Review Board Statement: Not applicable.

Data Availability Statement: Data is contained within the article and supplementary material.

Conflicts of Interest: The authors declare no conflict of interest.

\section{References}

1. Ford, R.C.; Beis, K. Learning the ABCs one at a time: Structure and mechanism of ABC transporters. Biochem. Soc. Trans. 2019, 47, 23-36. [CrossRef]

2. Xiao, Q.Y.; Zhou, Y.T.; Lauschke, V.M. Ethnogeographic and inter-individual variability of human ABC transporters. Hum. Genet. 2020, 139, 623-646. [CrossRef]

3. Dean, M.; Annilo, T. Evolution of the ATP-binding cassette (ABC) transporter superfamily in vertebrates. Annu. Rev. Genom. Hum. Genet. 2005, 6, 123-142. [CrossRef]

4. Dermauw, W.; Van Leeuwen, T. The ABC gene family in arthropods: Comparative genomics and role in insecticide transport and resistance. Insect Biochem. Mol. Biol. 2014, 45, 89-110. [CrossRef]

5. Bretschneider, A.; Heckel, D.G.; Vogel, H. Know your ABCs: Characterization and gene expression dynamics of ABC transporters in the polyphagous herbivore Helicoverpa armigera. Insect Biochem. Mol. Biol. 2016, 72, 1-9. [CrossRef] [PubMed]

6. Hollenstein, K.; Dawson, R.J.P.; Locher, K.P. Structure and mechanism of ABC transporter proteins. Curr. Opin. Struct. Biol. 2007, 17, 412-418. [CrossRef] [PubMed]

7. Saurin, W.; Hofnung, M.; Dassa, E. Getting in or out: Early segregation between importers and exporters in the evolution of ATP-binding cassette (ABC) transporters. J. Mol. Evol. 1999, 48, 22-41. [CrossRef] [PubMed]

8. Higgins, C.F. ABC transporters: From microorganisms to man. Annu. Rev. Cell Biol. 1992, 8, 67-113. [CrossRef]

9. Dassa, E.; Bouige, P. The ABC of ABCs: A phylogenetic and functional classification of ABC systems in living organisms. Res. Microbiol. 2001, 152, 211-229. [CrossRef]

10. Labbe, R.; Caveney, S.; Donly, C. Genetic analysis of the xenobiotic resistance-associated ABC gene subfamilies of the Lepidoptera. Insect Mol. Biol. 2011, 20, 243-256. [CrossRef]

11. Epis, S.; Porretta, D.; Mastrantonio, V.; Comandatore, F.; Sassera, D.; Rossi, P.; Cafarchia, C.; Otranto, D.; Favia, G.; Genchi, C.; et al. ABC transporters are involved in defense against permethrin insecticide in the malaria vector Anopheles stephensi. Parasites Vectors 2014, 7, 7. [CrossRef] [PubMed]

12. Pignatelli, P.; Ingham, V.A.; Balabanidou, V.; Vontas, J.; Lycett, G.; Ranson, H. The Anopheles gambiae ATP-binding cassette transporter family: Phylogenetic analysis and tissue localization provide clues on function and role in insecticide resistance. Insect Mol. Biol. 2018, 27, 110-122. [CrossRef] [PubMed]

13. He, C.; Liang, J.J.; Liu, S.N.; Wang, S.L.; Wu, Q.J.; Xie, W.; Zhang, Y.J. Changes in the expression of four ABC transporter genes in response to imidacloprid in Bemisia tabaci Q (Hemiptera: Aleyrodidae). Pest. Biochem. Physiol. 2019, 153, 136-143. [CrossRef] [PubMed]

14. You, M.S.; Yue, Z.; He, W.Y.; Yang, X.H.; Yang, G.; Xie, M.; Zhan, D.L.; Baxter, S.W.; Vasseur, L.; Gurr, G.M.; et al. A heterozygous moth genome provides insights into herbivory and detoxification. Nat. Genet. 2013, 45, 220-225. [CrossRef]

15. Mastrantonio, V.; Ferrari, M.; Epis, S.; Negri, A.; Scuccimarra, G.; Montagna, M.; Favia, G.; Porretta, D.; Urbanelli, S.; Bandi, C. Gene expression modulation of $\mathrm{ABC}$ transporter genes in response to permethrin in adults of the mosquito malaria vector Anopheles stephensi. Acta Trop. 2017, 171, 37-43. [CrossRef] [PubMed] 
16. Pan, Y.O.; Zeng, X.C.; Wen, S.Y.; Gao, X.W.; Liu, X.M.; Tian, F.Y.; Shang, Q.L. Multiple ATP-binding cassette transporters genes are involved in thiamethoxam resistance in Aphis gossypii glover. Pest. Biochem. Physiol. 2020, 167, 8. [CrossRef] [PubMed]

17. Figueira-Mansur, J.; Ferreira-Pereira, A.; Mansur, J.F.; Franco, T.A.; Alvarenga, E.S.L.; Sorgine, M.H.F.; Neves, B.C.; Melo, A.C.A.; Leal, W.S.; Masuda, H.; et al. Silencing of P-glycoprotein increases mortality in temephos-treated Aedes aegypti larvae. Insect Mol. Biol. 2013, 22, 648-658. [CrossRef]

18. Dalla Bona, A.C.; Chitolina, R.F.; Fermino, M.L.; Poncio, L.D.; Weiss, A.; Lima, J.B.P.; Paldi, N.; Bernardes, E.S.; Henen, J.; Maori, E. Larval application of sodium channel homologous dsRNA restores pyrethroid insecticide susceptibility in a resistant adult mosquito population. Parasites Vectors 2016, 9, 14. [CrossRef]

19. Xu, C.J.; Li, C.Y.T.; Kong, A.N.T. Induction of phase I, II and III drug metabolism/transport by xenobiotics. Arch. Pharm. Res. 2005, 28, 249-268. [CrossRef]

20. Despres, L.; David, J.P.; Gallet, C. The evolutionary ecology of insect resistance to plant chemicals. Trends Ecol. Evol. 2007, 22, 298-307. [CrossRef]

21. Lin, M.G.; Wang, X.-J.; Zhang, Y.; Sun, R.F.; Zeng, L. Optimization of artificial diets for mass rearing of Bactrocera dorsalis, Bactrocera cucurbitae and Bactrocera tau. Chin. J. Appl. Entomol. 2013, 50, 1115-1125. [CrossRef]

22. Koyama, J.; Kakinohana, H.; Miyatake, T. Eradication of the melon fly, Bactrocera cucurbitae, in Japan: Importance of behavior, ecology, genetics, and evolution. Annu. Rev. Entomol. 2004, 49, 331-349. [CrossRef] [PubMed]

23. Khan, M.H.; Khuhro, N.H.; Awais, M.; Memon, R.M.; Asif, M.U. Functional response of the pupal parasitoid, Dirhinus giffardii towards two fruit fly species, Bactrocera zonata and B. cucurbitae. Entomol. Gen. 2020, 40, 87-95. [CrossRef]

24. Wei, D.; Xu, H.Q.; Chen, D.; Zhang, S.Y.; Li, W.J.; Smagghe, G.; Wang, J.J. Genome-wide gene expression profiling of the melon fly, Zeugodacus cucurbitae, during thirteen life stages. Sci. Data 2020, 7, 9. [CrossRef]

25. Sim, S.B.; Geib, S.M. A Chromosome-scale assembly of the Bactrocera cucurbitae genome provides insight to the genetic basis of white pupae. G3-Genes Genomes Genet. 2017, 7, 1927-1940. [CrossRef]

26. Letunic, I.; Doerks, T.; Bork, P. SMART: Recent updates, new developments and status in 2015. Nucleic Acids Res. 2015, 43, D257-D260. [CrossRef] [PubMed]

27. Emanuelsson, O.; Nielsen, H.; Brunak, S.; von Heijne, G. Predicting subcellular localization of proteins based on their N-terminal amino acid sequence. J. Mol. Biol. 2000, 300, 1005-1016. [CrossRef]

28. Julenius, K.; Molgaard, A.; Gupta, R.; Brunak, S. Prediction, conservation analysis, and structural characterization of mammalian mucin-type O-glycosylation sites. Glycobiology 2005, 15, 153-164. [CrossRef]

29. Li, W.J.; Song, Y.J.; Han, H.L.; Xu, H.Q.; Wei, D.; Smagghe, G.; Wang, J.J. Genome-wide analysis of long non-coding RNAs in adult tissues of the melon fly, Zeugodacus cucurbitae (Coquillett). BMC Genom. 2020, 21, 600. [CrossRef] [PubMed]

30. Hellemans, J.; Mortier, G.; De Paepe, A.; Speleman, F.; Vandesompele, J. qBase relative quantification framework and software for management and automated analysis of real-time quantitative PCR data. Genome Biol. 2007, 8, 14. [CrossRef]

31. Ewart, G.D.; Howells, A.J. ABC transporters involved in transport of eye pigment precursors in Drosophila melanogaster. Methods Enzymol. 1998, 292, 213-224.

32. Tian, L.X.; Song, T.X.; He, R.J.; Zeng, Y.; Xie, W.; Wu, Q.J.; Wang, S.L.; Zhou, X.G.; Zhang, Y.J. Genome-wide analysis of ATP-binding cassette (ABC) transporters in the sweetpotato whitefly, Bemisia tabaci. BMC Genom. 2017, 18, 16. [CrossRef]

33. Sun, H.; Pu, J.; Chen, F.; Wang, J.; Han, Z. Multiple ATP-binding cassette transporters are involved in insecticide resistance in the small brown planthopper, Laodelphax striatellus. Insect Mol. Biol. 2017, 26, 343-355. [CrossRef] [PubMed]

34. Liu, X.Q.; Jiang, H.B.; Xiong, Y.; Peng, P.; Li, H.F.; Yuan, G.R.; Dou, W.; Wang, J.J. Genome-wide identification of ATP-binding cassette transporters and expression profiles in the Asian citrus psyllid, Diaphorina citri, exposed to imidacloprid. Comp. Biochem. Physiol. D Genom. Proteom. 2019, 30, 305-311. [CrossRef] [PubMed]

35. Liu, S.M.; Zhou, S.; Tian, L.; Guo, E.N.; Luan, Y.X.; Zhang, J.Z.; Li, S. Genome-wide identification and characterization of ATP-binding cassette transporters in the silkworm, Bombyx mori. BMC Genom. 2011, 12, 14. [CrossRef]

36. Xiao, L.F.; Zhang, W.; Jing, T.X.; Zhang, M.Y.; Miao, Z.Q.; Wei, D.D.; Yuan, G.R.; Wang, J.J. Genome-wide identification, phylogenetic analysis, and expression profiles of ATP-binding cassette transporter genes in the oriental fruit fly, Bactrocera dorsalis (Hendel) (Diptera: Tephritidae). Comp. Biochem. Physiol. D Genom. Proteom. 2018, 25, 1-8. [CrossRef] [PubMed]

37. He, Q.Y.; Yan, Z.T.; Si, F.L.; Zhou, Y.; Fu, W.B.; Chen, B. ATP-binding cassette (ABC) transporter genes involved in pyrethroid resistance in the Malaria cector Anopheles sinensis: Genome-wide identification, characteristics, phylogenetics, and expression profile. Int. J. Mol. Sci. 2019, 20, 1409. [CrossRef]

38. Mackenzie, S.M.; Brooker, M.R.; Gill, T.R.; Cox, G.B.; Howells, A.J.; Ewart, G.D. Mutations in the white gene of Drosophila melanogaster affecting ABC transporters that determine eye colouration. Biochim. Biophys. Acta Biomembr. 1999, 1419, 173-185. [CrossRef]

39. Yu, Z.T.; Wang, Y.W.; Zhao, X.M.; Liu, X.J.; Ma, E.B.; Moussian, B.; Zhang, J.Z. The ABC transporter $A B C H-9 C$ is needed for cuticle barrier construction in Locusta migratoria. Insect Biochem. Mol. Biol. 2017, 87, 90-99. [CrossRef]

40. Broehan, G.; Kroeger, T.; Lorenzen, M.; Merzendorfer, H. Functional analysis of the ATP-binding cassette (ABC) transporter gene family of Tribolium castaneum. BMC Genom. 2013, 14, 18. [CrossRef]

41. Jin, M.H.; Liao, C.Y.; Chakrabarty, S.; Zheng, W.G.; Wu, K.M.; Xiao, Y.T. Transcriptional response of ATP-binding cassette (ABC) transporters to insecticides in the cotton bollworm, Helicoverpa armigera. Pest. Biochem. Physiol. 2019, 154, 46-59. [CrossRef] 
42. Zhou, A.M.; Hassel, B.A.; Silverman, R.H. Expression cloning of 2-5a-dependent Rnase-A uniquely regulated mediator of interferon action. Cell 1993, 72, 753-765. [CrossRef]

43. Denecke, S.; Fusetto, R.; Batterham, P. Describing the role of Drosophila melanogaster ABC transporters in insecticide biology using CRISPR-Cas9 knockouts. Insect Biochem. Mol. Biol. 2017, 91, 1-9. [CrossRef] [PubMed]

44. Guo, Z.J.; Sun, D.; Kang, S.; Zhou, J.L.; Gong, L.J.; Qin, J.Y.; Guo, L.; Zhu, L.H.; Bai, Y.; Luo, L.; et al. CRISPR/Cas9-mediated knockout of both the PxABCC2 and PxABCC3 genes confers high-level resistance to Bacillus thuringiensis Cry1Ac toxin in the diamondback moth, Plutella xylostella (L.). Insect Biochem. Mol. Biol. 2019, 107, 31-38. [CrossRef] [PubMed]

45. Jones, C.M.; Toe, H.K.; Sanou, A.; Namountougou, M.; Hughes, A.; Diabate, A.; Dabire, R.; Simard, F.; Ranson, H. Additional selection for insecticide resistance in urban Malaria Vectors: DDT Resistance in Anopheles arabiensis from Bobo-Dioulasso, Burkina Faso. PLoS ONE 2012, 7, e0045995. [CrossRef]

46. Strycharz, J.P.; Lao, A.; Li, H.M.; Qiu, X.H.; Lee, S.H.; Sun, W.L.; Yoon, K.S.; Doherty, J.J.; Pittendrigh, B.R.; Clark, J.M. Resistance in the highly DDT-resistant 91-R strain of Drosophila melanogaster involves decreased penetration, increased metabolism, and direct excretion. Pest. Biochem. Physiol. 2013, 107, 207-217. [CrossRef]

47. Li, Z.; Cai, T.W.; Qin, Y.; Zhang, Y.H.; Jin, R.H.; Mao, K.K.; Liao, X.; Wan, H.; Li, J.H. Transcriptional response of ATP-binding cassette (ABC) transporters to insecticide in the brown planthopper, Nilaparvata lugens (Stal). Insects 2020, 11, 280. [CrossRef] [PubMed]

48. Wu, C.T.; Budding, M.; Griffin, M.S.; Croop, J.M. Isolation and characterization of Drosophila multidrug resistance gene homologs. Mol. Cell. Biol. 1991, 11, 3940-3948. [CrossRef] [PubMed]

49. Vache, C.; Camares, O.; Cardoso-Ferreira, M.C.; Dastugue, B.; Creveaux, I.; Vaury, C.; Bamdad, M. A potential genomic biomarker for the detection of polycyclic aromatic hydrocarbon pollutants: Multidrug resistance gene 49 in Drosophila melanogaster. Environ. Toxicol. Chem. 2007, 26, 1418-1424. [CrossRef] [PubMed]

50. Wang, L.; Johnson, Z.L.; Wasserman, M.R.; Levring, J.; Chen, J.; Liu, S.X. Characterization of the kinetic cycle of an ABC transporter by single-molecule and cryo-EM analyses. eLife 2020, 9, e56451. [CrossRef] [PubMed]

51. Koenig, C.; Bretschneider, A.; Heckel, D.G.; Grosse-Wilde, E.; Hansson, B.S.; Vogel, H. The plastic response of Manduca sexta to host and non-host plants. Insect Biochem. Mol. Biol. 2015, 63, 72-85. [CrossRef] [PubMed]

52. Meng, X.K.; Yang, X.M.; Wu, Z.L.; Shen, Q.W.; Miao, L.J.; Zheng, Y.; Qian, K.; Wang, J.J. Identification and transcriptional response of ATP-binding cassette transporters to chlorantraniliprole in the rice striped stem borer, Chilo suppressalis. Pest Manag. Sci. 2019, 76, 3626-3635. [CrossRef] [PubMed] 